\title{
7 Frequently Asked Questions (FAQs) in Urban Planning
}

\author{
Tüzin Baycan Levent* and Peter Nijkamp**
}

\begin{abstract}
Urban planning has, in its rich history, often been reviewed from the perspective of different philosophical, ideological and methodological approaches by planners, architects and social scientists. In this paper, we aim to highlight the debate on urban planning in the context of planning history and to address some of the most fascinating questions asked in the urban planning literature. We focus on 7 FAQs in urban planning, while we address 7 differently given answers for each question. Therefore, our tree-like exercise consists of $7 \times 7=49$ different approaches to urban planning. Our questions are derived from planning theory and practice, planning methodology and techniques, urban development, urban management and urban future. The paper will be concluded with a concise speculative agenda for the future of urban planning.
\end{abstract}

JEL Classification: O18, R14

Keywords: Urban Planning, Planning History, Classics, Trends in Planning, Urbanization, Land Use, New Towns

\section{Prefatory Remarks}

\section{A Conservationist's Lament}

The World is finite, resources are scarce,

Things are bad and will be worse,

Coal is burned and gas exploded,

Forests cut, and soils eroded,

Wells are dry and air's polluted,

Dust is blowing, trees uprooted,

Oil is going, ores depleted,

Drains receive what is excreted,

Land is sinking, seas are rising,

Man is far too enterprising,

Fire will rage with Man to fan it,

Soon we'll have a plundered planet,

People breed like fertile rabbits,

People have disgusting habits.

\footnotetext{
* Department of Urban and Regional Planning, Istanbul Technical University, Istanbul, Turkey, tuzin. baycanlevent @itu.edu.tr

** Department of Spatial Economics, Free University, Amsterdam, The Netherlands, pnijkamp@ feweb. vu.nl
}

Received : 21 August 2007 Accepted : 20 April 2008

(C) 日本地域学会 (JSRSAI) 2008 
Moral 'The evolutionary plan-went astray

by evolving Man'.

Source: Kenneth Boulding, In: Travis, A.S. (1977)

The Technologist's Reply

Man's potential is quite terrific,

You can't go back to the Neolithic,

The cream is there for us to skim it,

Knowledge is power and the sky's the limit,

Every mouth has hands to feed it,

Food is found when people need it,

All we need is found in granite,

Once we have the men to plan it,

Yeast and algae give us meat,

Soil is almost obsolete,

Men can grow to pastures greener,

Till all the earth is Pasadena.

Moral 'Man's a nuisance, Man's a crackpot,

But only Man can hit the jackpot'.

Source: Kenneth Boulding, In: Travis, A.S. (1977)

Planning has a rich history as a profession-more than as a discipline. It has often been an instrument in the hands of policy-makers, rather than an independent science serving the needs of people. The substance and scope of planning have, consequently, met much criticism or at least critical reflection. In the planning history, at least seven different dimensions of - or perspectives on-planning can be distinguished:

- a blueprint view, with a clear top-down command and control ambition

- a rationality view, based on the intensification of logical action derived from the maximization of social objectives

- a bounded rationality view, which takes for granted that the rigorous pursuit of social goals to be maximized may incur high transaction costs

- a procedural viewpoint, where planning is seen as the obedient application of a set of protocols and rules

- an accountability perpective, which takes for granted that any planning action is correct if it can be justified on logical or scientific grounds

- a sustainability perspective in which planning should serve the needs of ecologically -benign development of society

- a people's perspective in which planning meets the conditions for greater utility (or happiness) of people. 
It is noteworthy that over the years planning has not developed as an unambiguous scientific discipline, but more as a coherent set of actions (incorporating different disciplines) geared towards change management of society. In general, planning is the science of rational change and action, from the perspective of objectives deliberately set by the agency in charge. Interventions of various forms and nature are deployed to move the state of a relevant system from one existing state to a future and more acceptable state (Travis, 1977). The main problem is that there is not a uniformly accepted desirable state, so that normally any attempt to change the order of things will meet fierce resistance based on dynamic (or

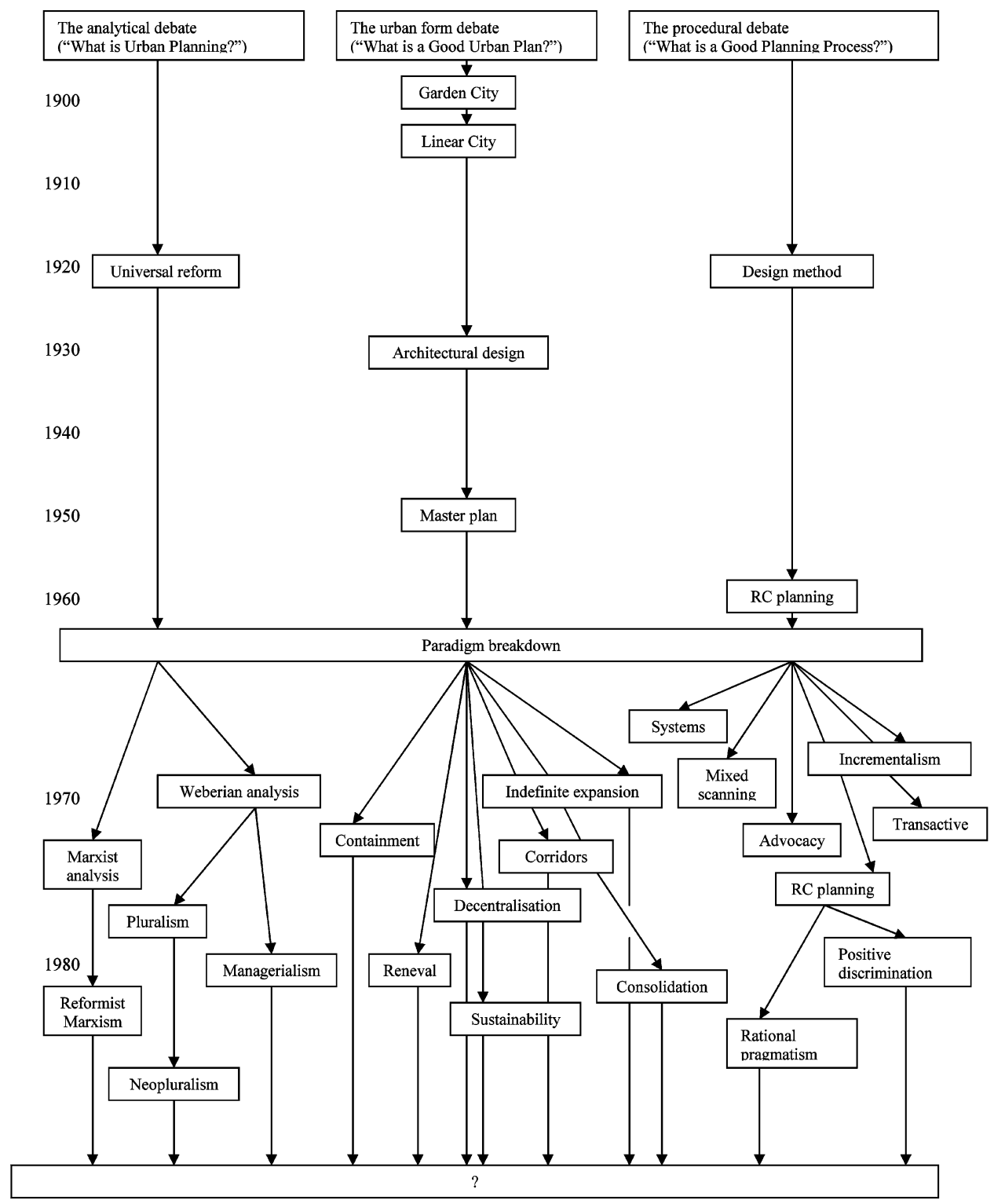

Figure 1 The evolution of the three debates of planning theory (after Yiftachel, 1989) 
resilient) conservatism.

The above remarks hold also for urban planning, which is the subject of the present paper. The latter discipline has demonstrated a dynamic development path that runs largely parallel to major trends in the general planning literature. Figure 1 maps out the structure of the various issues and approaches in urban planning in the past century. The belief in 'control and command' policies has, in the past decades, given way to evolutionary and participatory planning principles. Utopian planning (à la Thomas More or Charles Fournier) has been given up in favour of planning for the people as part of a democratic process with transparant choices. Nevertheless, there is still much debate on the substance and scope of urban planing. This debate appears to have centered around seven major strategic issues, which are treated here as 7 FAQs (frequently asked questions) in urban planning:

1. What is planning?

2. What are the trends and the changing context in urban planning theory and practice?

3. What is a good urban plan?

4. What are the key characteristics (the significant current trends, countertrends, the potential for change and the alternative directions) of a future urban structure?

5. What are the urbanization trends in the Developing World?

6. How may planning methods and techniques be used with greater effectiveness?

7. What is a good planning process at the interface of citizen participation and urban governance?

Why are there 7 FAQs and why are these 7 FAQs selected for this paper? The number of questions, of course, could be easily increased, for example, to 10 and the title of this paper could be "Top 10 Issues in Urban Planning". We have selected 7 FAQs because there are seven days in a week, there are seven wonders of the world, there are seven deadly sins (in theology, causing spiritual death : pride, covetousness, lust, anger, gluttony, envy and sloth), there are seven seas (all the oceans of the world), there are seven stars (same as Pleiades, in Greek mythology, the seven daughters of Atlas and Pleione, who were placed by Zeus among the stars), there are Seven Hills of Rome, and according to astronomy and certain theologies there exists the seventh heaven. We have selected 7 FAQs because we aim to address 7 FAQs, while we address 7 differently given answers for each question. While our 7 questions are general, the given 7 answers for each question consider some specific questions as well.

We will highlight these questions by means of existing contributions from the literature on urban planning, which are selected after a careful screening process. The selected articles as well as the questions asked in each paper reflect the debate about urban planning from the perspectives of planning theory and practice, planning of urban settlements, future urban structure, urban planning in the developing world, urban planning models and community involvement in urban planning from the 1950s to the new millennium. We will in particular look at ideas found in influential or classic articles on urban planning. Clearly, it is not an easy task to decide what is important or classic. A classic article can be defined by the number of citations, by the researchers or scientists who have become 'classic' in the 
field, or by the journals which have broadly been accepted as 'classic'. A classic article can be seen as an article which has created a debate and has had an impact on the field. A classic article can also be seen as an 'old' influential article; clearly, when one accepts that to become a 'classic' needs time. In the selection of articles for this paper on urban planning, we have taken into consideration various aspects and we have tried to include those articles that were mostly cited, were written by famous scientists and planners, were published by different international journals in the field and have, therefore, reflected different approaches. We have of course benefited also from the 'classic' articles selected by the journals themselves, or the 'top ten', 'top fifty' or 'most downloaded' articles defined by journals. These kinds of lists have been very helpful in our selection process. However, in the composition of the present paper we have tried to include the different approaches of various institutions or scientists to the urban planning debate in a time perspective. In order to position the actual debate as well as to follow the continuity of the debate in the last fifty years, we have also selected some relatively 'new' articles published after 2000. We have tried to consider a broad geography including the western world from the United States to Europe as well as the developing world in order to highlight the different experiences of both developed and developing countries. Nevertheless, a high priority was given to those articles that had a more general nature instead of a focus on a specific country.

Undoubtedly, there are many ways to compose a collection of 'classic' contributions to urban planning, and our selection is, of course, subjective in its nature. Nevertheless, our collection offers, in a limited way, some of the most fascinating questions asked in the urban planning literature.

\section{What is planning?}

"What is planning ?" This question has been a central question in the urban planning literature over the years. Its multidisciplinary nature, comprehensive perspective, changing character and continued self-questioning render any attempt to define urban planning difficult. However, the concept has been defined in various ways in order to consider a multiplicity of dimensions. Some of the definitions are :

- "Planning is the process by which he selects a course of action (a set of means) for the attainment of his ends." (Banfield, 1959).

- "Planning can be used as a generic term to denote a certain kind of decision making process which is applicable in a wide variety of situations.” (Wilson, 1968).

- "... planning is a process, a process of human thought and action based upon that thought - in point of fact, forethought, thought for the future-nothing more or less than this is planning, which is a general human activity." (Chadwick, 1971).

"Planning is future-oriented, and thus optimistic, for it assumes man's ability to control his own destiny, at least within certain limits" (Chadwick, 1971).

- Planning is “. . . an activity concerned with making choices about future options, taking into account probabilities and the value of what may be achieved, and then securing the implementation of the chosen option" (Roberts, 1974).

- “... planning as a general activity is the making of an orderly sequence of action that will lead to the achievement of a stated goal or goals” (Hall, 1992). 
“... urban planning ... refers to planning with a spatial, or geographical, component, in which the general objective is to provide for a spatial structure of activities (or of land uses) which in some way is better than the pattern existing without planning" (Hall, 1992).

- "Planning in its generic meaning, then, is a ubiquitous activity. Cutting accross all types of planning is a certain common denominator. All have in common a conscious effort to define systematically and think through a problem to improve the quality of decision making." (Levy, 1997).

- "Planning is the organization of hope." (Forester, 1999).

Urban planning is a mixture of science and art. It encompasses many different disciplines and brings them all under a single umbrella. The simplest definition of urban planning is that it is the organization of all elements of a city or other urban environments. However, when one thinks about all the elements that make up a city, urban planning suddenly seems rather complicated, and actually it is. Nowadays, urban planning takes all relevant aspects of a city into consideration.

Urban planning as a very wide and a multidimensional concept and the discipline covers a field ranging from land use to transportation, from environment to social and economic life, and from neighbourhood level to regional or national level from the perspective of human settlements. Urban planning deals with everything at the interface of human settlements and human life. Urban planning considers everything in between urban design and macro planning or national planning which includes also policy issues from local to central goverment as well as public-private partnership, community involvement in the planning process and urban governance. This multidimensional nature of urban planning makes a holistic approache desirable, on the basis of the view on the urban system as an entire and complex system.

As a result, the literature on urban planning demonstrates that there is no single definition of planning and it seems that main question of the planning literature "What is planning ?" will continue to be asked from different perspectives and changing contexts in the future as well. Increasing complexity, dynamism and the multidimensional nature of planning may also contribute in the future to widen and enrich the definition and the context of planning.

\section{What are the trends and the changing context in urban planning theory and practice?}

“... we will keep on writing planning theory, because it's fun ... at least, for some of us. Vladimir Nabokov loved to collect butterflies. We, who are not Nabokov, go hunting for exotic species of ideas, more specifically, ideas about the practice of what still goes by the name of planning." (Friedmann, 1998, pp. 250). In order to give a place for 'funny' activities of planners and to go 'hunting for exotic species of ideas', it is necessary to address substantive questions related to planning theory and practice. Therefore, the present section aims to offer a better understanding of the trends and the changing context in urban planning theory and practice. The seven selected articles and questions reflect the debate in planning theory and practice from the end of 1950s to the beginning of the new millennium. 
- In order to understand the varied effects of different physical forms, and of the location of human activities in relation to physical form, Lynch and Rodwin (1958) examine possible analytical approaches while concentrating in particular on the need for analyzing urban form in relation to goal formulations. They discuss techniques for studying the interrelations between such forms and goals, and the possible implications of this new approach for theory, research, and practical planning decisions. They propose to set an approach which will deal first with the problem of analyzing urban form, secondly with the formulation of goals, and thirdly with the techniques of studying the interrelations between such forms and goals.

- A second article in our selection, written by Muller (1998), discusses the conceptual and contextual considerations of paradigms and planning practice. On the basis of Thomas Kuhn's paradigm concept, he examines the validity of the paradigmatic principles in their application to social science disciplines as well as planning. He advocates that the planning's professional and intellectual legitimacy requires theoreti$\mathrm{cal} /$ methodological foundations, while the characteristics of planning are incompatible with the precepts of Kuhn's paradigm. He emphasizes the need for an alternative model to provide planning with a tenable theoretical and practical base.

- "Are planners obliged to serve the interests of their political employers, the organisation, personal values, clients, the wider community, future generations or the profession?", and "How are practitioners coping with the contexts in which they find themselves and what values and methods are guiding their actions?". Campbell and Marshall (1998) address the nature of planning on the basis of moral judgements and ethical questions and the principles which should guide practice. They focus mainly on the appropriateness of action, most particularly the means adopted, or the intrinsic value of the underlying ends and goals and underlying obligations. They highlight some of the tensions between different values and between values, means and obligations and dilemmas at the heart of contemporary practice.

- "Why, after five decades of active theorizing, it is still impossible for people engaged in writing planning theory to agree on a formal definition of their subject?" In his interesting article, Friedmann (1998) answers this question by addressing four difficulties in planning discourse: "the problem of defining planning as an object to be theorized; the impossibility of talking about planning disconnected from actual institutional and political contexts ; the several modes of doing planning theory normative, positive, critical, and paradigm-shifting and the dilemma of choosing among them; and last but not least, the difficulty of incorporating power relations into planning discourse." He proposes that the three themes: the production of the urban habitat, the rise of civil society, and the question of power should get a central position in theorizing.

- In his article on the future understanding of planning practice, Forester (1999) focuses on three issues, practical anticipation, political power, and value difference, while he addresses the avoidance of planners from the issues of power and value in planning practice. He argues that this avoidance of value inquiry and value-critical argumentation hinders planners in their inevitably evaluative work, confuses respect for 
different persons with agreement on different ideas, and also conservatively weakens the hand of those with legitimate rather than narrowly self-serving needs.

- In a next contribution, Graham and Healey (1999) examine relational concepts of space and place from the perspective of planning theory and practice. "In a world of tumultuous economic, social, cultural, technological and physical change, how can we best conceptualize the dynamics of places and the role of planning action in shaping them ?", and "... how might spatial planners translate new understandings of sociospatial relations into their practices?" In order to answer these questions, they conceptualize and explore the changing relationships between planning action and practice and the dynamics of place. While criticizing the legacy of object-oriented, Euclidean concepts of planning theory and practice, they focus, in particular, on relational theories of urban time-space, dynamic conceptualizations of multiplex places and cities, the new urban and regional socio-economics and emerging theories of social agency and institutional ordering.

- “How can strategic plans be evaluated ?”, "What is the purpose of spatial planning at the more strategic level of regional and even more so national planning ?", "What is the best approach to evaluating 'planning-as-learning'?", "What is the appropriate method for evaluating the 'performance' of planning as a learning process ?", "What makes actors involved in spatial development invoke a common frame of reference?", and "Is the purpose of planning to articulate a doctrine or frame that gains acceptance, and where does this leave other criteria of good planning?" On the basis of these questions Faludi (2000) examines in his article the performance of spatial planning. He argues that strategic spatial plans must be evaluated, not primarily in the light of their material outcomes, but for how they improve the understanding of decision makers of present and future problems they face. He emphasizes that when plans increase this understanding and when they help decision makers make sense of their situations, they perform their role. Faludi ends his article with an exposition of 'planning doctrine' and its implications for evaluation research.

This overview of trends and of the changing context in urban planning theory and practice highlights a shift with more focus over the years from methods guiding the actions to values, moral judgments and ethical questions and principles guiding practice. Power relations, and institutional and political contexts also seem to gain more importance besides economic, social, cultural and technological changes and dynamics and their impacts on planning practice.

\section{What is a good urban plan?}

This section offers a wide spectrum of diverse views on urban settlements, from neighbourhood to new town planning level, and from economic base to environmental quality and city size. In the selection of the various contributions we aim to deal with different planning activities at different levels as well as different discussions in different periods.

- In an original contribution, Mumford (1953) discusses the arguments for and against neighbourhood planning such as segregation, social impoverishment and social integration. While examining the development of the new concept of the neighbourhood as 
a complete unit in planning, he evaluates the discussion whether neighbourhoods actually exist, particularly within great cities, or whether neighbourhoods are the willful mental creations of romantic sociologists. He aims to clarify the confusing issues in neighbourhood planning and to argue that it is possible to take a more rational position on one or the other side.

- The economic base-in other words, the basic/primary employment or economic activity including 'export industries' of a metropolitan area-has been an important question in planning and related fields. "What is the relative importance of "basic and "nonbasic" activities in a metropolitan area ?" Blumenfeld (1955) discusses in his article basic and nonbasic (or primary and secondary) economic activities of metropolitan areas on the basis of distinctions into basic-nonbasic ratios, multipliers, critical industries, export industries, balance of payments, and indirect primary activities. After his evaluation, he concludes that although the basic-nonbasic method has a great value for the development of balance-of-payments studies and for the exploration of the criticality of various industries, it is useless as a tool for predicting the population of metropolitan areas and as a guide for the concentration of local promotional efforts.

- One of the most influential books in urban planning, undoubtedly, is "The Death and Life of Great American Cities" of Jane Jacobs (1961). Her book which focuses on what makes a city and what function serves within the city has become a classic since its first publication in 1961. In her study, Jacobs asks one of the most important questions about planning cities: "How can cities generate enough mixture among uses - enough diversity- throughout enough of their territories, to sustain their own civilization?" While emphasizing that the essential phenomenon is to deal with combinations of mixtures of uses which need an enormous diversity of ingredients, she defines the conditions - or in other words-generators of diversity.

- The new towns movement began with Ebenezer Howard's proposal for garden cities and developed to provide an alternative to the overgrowth, congestion, and suburban sprawl of cities by creating new moderate-sized towns in which people can have good homes in healthy and pleasant surroundings near their places of work, with urban services and cultural facilities and access to the open countryside. "What are new towns for?" In order to answer this question Alonso (1970) examines the stated purposes of a new towns strategy in America as a rational policy in the public interest. He evaluates the principal objectives for new towns on the basis of three categories, viz. macro geo-economic purposes, social policy purposes, and production and physical purposes. He concludes that there is little force in the arguments for a major commitment of effort and resources to direct a substantial portion of urbanisation into new towns, and there may be some sense in the limited use of new towns for the testing and development of technological, physical, and institutional innovations which might be applicable to the expansion and rebuilding of existing cities.

- "Is there an optimal city size and/or an optimal distribution of city sizes ?", "How true is the widespread belief that the large city makes a much greater contribution to national growth than to the welfare of its citizen?", "What are the implications of findings on these questions for formulating a national urban policy ?" In his fascinat- 
ing study, Richardson (1972) deals with optimality in city size. He addresses the concept of optimal city size, while reviewing the literature on the national urban hierarchy as well as the goals and instruments of urban policy and policy implications.

- The next contribution from Rappoport (1983) addresses environmental quality, metropolitan areas and traditional settlements. His study examines the cultural landscape from the perspective of preservation and conservation, while focusing on the choices made by different groups which affect the way the people interact, structure space and time and many other characteristics. The main question posed is why certain principles of traditional cultural landscapes need to be preserved so that their lessons about environmental quality can be applied to the planning and design of urban areas - at all scales - in the future. The study calls attention for the lessons to be learned from traditional settlements.

- “Are compact cities a desirable planning goal ?" In order to evaluate whether or not the promotion of compact cities is a worthwhile planning goal, Gordon and Richardson (1997) examine in their article several issues relevant to the compact cities discussion, such as the pressures on primary agricultural land, residential density preferences, energy resource savings, the potential for expanding transit use and promoting transitoriented developments, the costs and benefits of suburbanization, the efficiency gains from compactness, the impact of telecommunications on the density of development, the social equity of compactness, and the effects of competition among cities. Their evaluation on the basis of these key issues does not support the case for promoting compact cities. While drawing attention to inevitable problems with how we manage the highway system, negative externalities and urban service delivery systems, they mention that a reversal of existing urban development trends is neither feasible nor desirable.

It is obvious that the question of "What is a good urban plan?" has been one of the main questions in the urban planning literature. All planning efforts from neighbourhood to city level have aimed to achieve the 'good' or 'best' urban development alternatives. In other words, the main aim of planning activities has always been to increase the quality of urban life over the years. For a better quality of life sometimes planning has focused on different functions of cities and sometimes on the size, compactness or alternatively the "new" forms (new towns) of cities. Quality of life will be in the mainstream of urban planning in the future as well and looking for a better living conditions will be always at the top of the agenda of future planning.

4. What are the key characteristics (the significant current trends, countertrends, the potential for change and the alternative directions) of a future urban structure?

"Planning is future-oriented, and thus optimistic, for it assumes man's ability to control his own destiny, at least within certain limits" (Chadwick, 1971). Planning is “... an activity concerned with making choices about future options, taking into account probabilities and the value of what may be achieved, and then securing the implementation of the chosen option" (Roberts, 1974). As planning deals with future states, planners have oriented themselves to the future urban structure throughout the planning history. This section 
offers some 'futuristic' articles. The selected contributions focus on the present trends at the time as well as on the potential change and future trends, while they also describe relevant urban policies for the future.

- Wurster (1963) addresses the form and structure of the future urban complex. She suggests a range of alternatives for the spatial organization of the future urban complex, with some of their possible implications. "What are the significant current trends and the forces behind them ?", "What are the resulting problems and conflicts which could change the present picture?" On the basis of these questions she evaluates the trends, countertrends, and the potential for change and the alternative directions for form and structure.

- Undoubtedly, the key characteristic for the future urban structure is the sustainability goal. Sustainability does not only refer to the ongoing urban process, actual problems and needs, but also to the future needs and the way and the direction of development for the future. Therefore, it is the main concept which refers to the future in urban planning. Choguill (1993) addresses in his article the issue of sustainable cities and he describes four necessary criteria including ecological, economic, social and technical sustainability in order to achieve urban sustainability. He evaluates urban policies for the future, in particular, future solutions to the issue of urban sustainability on the basis of four important policy areas, viz. the way goods and services are produced, meeting the basic human needs, an integrated urban and rural system as well as a balanced spatial development, and international cooperation.

- Next, Graham and Marvin (1994) address the implications of telematics and the convergence of urban infrastructure for the development and planning of contemporary cities. They analyse the revolutionary changes underway in the development of infrastructure services while taking into consideration privatisation and liberalisation in the 1980s in the UK. They focus on urban utility networks and the central role that modern information and communications technologies are playing in the restructuring of these crucial services.

- Hall (1997), in his article on the future of the metropolis and its form, discusses the economics of alternative patterns of land use and development on the basis of the Anglo-American debates from the 1960s and 1970s as well as the British experiments in the late 1980s and early 1990s. He summarizes the debate on sustainable urban development, while looking at some relevant European policy initiatives on sustainable urban transportation and land use.

- "Are cities dying ?", "Will the 21st century see a decline in urbanization as rapid as the rise in urbanization over the 19th and 20th centuries?" Glaeser (1998) presents a panoramic view of the primary economies and diseconomies of urban size. He argues that predicting the future of the city requires a framework for understanding the costs and benefits of urban life. He emphasizes that the future of the city's productivity depends on whether available substitutes for face-to-face interactions (e-mail, the internet, and so on) will make the need for personal contact obsolete, or whether the new technologies harbor the dawn of a more interactive era where the ability to contact in person easily is particularly prized. He emphasizes that the future of cities 
depends also on what governments do.

- "Will improvements in information technology eliminate face-to-face interactions and make cities obsolete?” In order to answer this question Gaspar and Glaeser (1998) discuss two opposing effects on cities and face-to-face interactions related to the improvements in telecommunication technology. They discuss whether improved technology implies that people will be more likely to use technology rather than faceto-face interaction or whether improved technology will lead to more relationships and subsequent face-to-face meetings. They focus on whether improvements in telecommunications technology is a substitute for meeting face-to-face or complementary. The results of their study show that telecommunications may be a complement to cities and face-to-face interactions. While improvements in telecommunications technology may increase the number of face-to-face interactions and the relevance of cities, an improvement in telecommunications will make cities more appealing in the future and improvements in information technology will further the economic role of cities.

- Finally, Sassen (2001), in her contribution based on the updated edition of "The Global City", discusses the impacts of information technologies on urban economies and politics. She addresses the intensity, complexity and global span of cross-border and digital networks and the new urban spatiality produced.

This overview of the key characteristics of a future urban structure draws attention to two main debates in the urban planning literature, one is on the future of 'physical space' and the other one is on the future of 'digital space'. Whereas physical space refers to the debate on sustainability, digital space refers to the development in information technology. The big debate about sustainability and our common future highlights four necessary criteria of ecological, economic, social and technical sustainability, whereas the other big debate, the impacts of the developments in information technology on urban life, addresses mainly the future of face-to-face interactions and the role of digital networks in the new urban space. These two key characteristics of a future urban structure seem to be the major issues of future planning for a long time to come.

\section{What are the urbanization trends in the Developing World?}

The immediate and most critical urban and environmental problems facing Third World cities such as lack of safe water supply, pollution, inadequate waste management, accidents linked to congestion and overcrowding and occupation and degradation of environmentally sensitive lands, constitute the 'brown agenda' of urban planning. This 'brown agenda' calls for preventive and curative measures to be developed by planners and policy-makers in response to the complex issues of rapid urbanization, poverty and environment. Urban development in the Third World cities has gained a special importance, in particular, since 1992, and the last decades have seen many activities highlighting the environmental dimension of urban development. This section will present different approaches to Third World cities from the perspective of sustainable urban development and environmental management. The selected contributions focus, on the one hand, on general development trends in the Third World and similarities between the countries, and on the other hand, on the 
enormous diversity as well as differences within Third World countries.

- In a contribution written by Hardoy and Satterthwaite (1986), the authors examine urban change in the Third World. "Are recent trends a useful pointer to the urban future ?", "How reliable are the statistics used for international urban comparisons ?", "What generalisations are valid as to urbanisation in the Third World ?". On the basis of these questions Hardoy and Satterthwaite focus on urban processes in the Third World, discuss generalisations about urban processes in the Third World, and highlight the enormous diversity within the Third World.

- In view of the growing environmental crisis of the Third World, Bartone (1991) draws attention to a new dimension, i.e., the environment, in sustainable development which recognizes the cycle of poverty, resource depletion, and environmental degradation in less developed countries. While mentioning that a sustainable development approach is urgently needed in the management of the urban environment, he suggests an approach that ensures the contribution of Third World cities to national economic development, while protecting the urban poor from the consequences of environmental deterioration. He advocates that environmental issues must be an integral part of all Third World urban policy.

- Next, Turner (1992) highlights the lessons from experiences in urban planning in the developing world. He focuses on the central question of whether planning as an activity practised in the customary way has a measurable (or even discernible) effect on the processes of urban growth, while addressing several case studies including Caracas, Madras, and the Philippines.

- The contribution by Leitmann and his associates (1992) aims to constitute a comprehensive, consistent approach to the environmental issues faced by cities in Third World countries. Stemming from a report entitled "Environmental Strategies for Cities : A Framework for Urban Environmental Planning and Management in Developing Countries", the article reflects the approach of UNDP/World Bank/UNCHS (Habitat) and provides the outline of a strategic approach to defining and addressing priority environment-related problems of urban development.

- A following article originates from Gilbert's (1992) triology on Third World cities. The author discusses the issues of housing, infrastructure and servicing and argues that economic conditions in most less-developed countries have deteriorated during the 1980 s and, that as a consequence of that deterioration, the corpus of planning recommendations has changed. On the basis of his overviews, he emphasizes that the three continents, Asia, Africa and Latin America and the Caribbean, show more differences than similarities, although there are important variations within continents such as the Asian countries Saudi Arabia and India.

- The next contribution discusses the strategic decisions for sustainable urban development in the Third World. White (1994) argues that a focus on urban ecosystems may suggest some ways of beginning a constructive approach to the problems of the very high level of resource use associated with the lifestyle of the North and the continuing rapid growth of population in the South.

- Finally, Drakakis-Smith (1995) follows a similar way as his predecessor Alan Gilbert 
and focuses on the conditions of sustainable urban development in Third World cities. He criticizes the approach of the World Bank and UNDP which relates urbanisation with development and concludes that the latter results from the productivity of economic activities in expanding cities, and emphasizes that the data used to verify such claims do not relate to urbanisation but to urban population growth, and not to development but to the surrogate GNP per capita. While drawing attention to the complex relationship between development and urban growth, he conceptualises sustainable urban development at two levels, the 'macro-level' (which refers to a philosophical approach to policy and management issues) and the 'micro level' (which identifies the major components of a comprehensive and integrative programme of sustainable urban development).

The "brown agenda" of urban planning will keep its importance in the planning literature as long as urban population continues to grow and concentration in urban areas continues to increase, in particular in the Third World. The increasing differences between both the developed and the developing world, and within the developing world itself, will deepen also the debate on the brown agenda. Especially the differences emerging between the developing countries seem to become the most important topic in this field. The political considerations as well as international negotiations and regulations will, of course, accompany this debate.

\section{How may planning methods and techniques be used with greater effectiveness ?}

Planners use their models to examine, and subsequently to make statements about, the real world that will assist them in controlling and changing events in the real world. The use of models can help the planner to understand and predict the behaviour of urban systems. Urban planning models are employed throughout the planning process at such stages as survey, systems analysis, forecasting, plan generation, evaluation, participation, decisiontaking, budgeting, implementation and monitoring. Since the $1960 \mathrm{~s}$ there has been an increasing interest in, and use of, quantitative models of urban and regional systems. A range of techniques has been devised to assist in analysis and experimentation and to distinguish the various activities that determine the nature of the human environment as well as to understand their relationships.

The selected contributions in this section focus mainly on the use and effectiveness of models in urban planning instead of on technical details of a specific model. Therefore, the articles can be evaluated as a reflection of internal debate among planners. They offer, on the other hand, a framework for the assessment of planning models and techniques in a historical perspective.

- The first article discussed in this set and written by Harris (1960) discusses the questions that the models raise. The article reflects the atmosphere of debates in city planning in the 1960s, while addressing whether the reorientation of planning leads to a fragmentation of the profession or to its coherent advancement.

- Next, Chapin (1963) focuses on the questions of "What are the techniques that have been used to date in regulating, directing, or in other ways influencing urban expansion ?", "How might they be used with greater effectiveness ?" Chapin emphasizes that 
the planning profession needs to take stock of techniques available to guide the tremendous growth in urban areas and suggests a 'guidance systems' approach as a means of relating and using these techniques in a more effective manner. His guidance system includes an urban development policies instrument, an area-wide public works programme, an urban development code and a metropolitan area programme of civic education as integrated and related subsystems.

- Wilson (1968) next sets up a conceptual framework for planning which is based on the use of a hierarchical relevance tree within which the use of models can be studied. He reviews the recent literature on the development of models which covers population and economic systems, urban structure, transport and social systems and discusses the possible applications of models in the design and planning process.

- In the following two articles Batey and Breheny (1982), and Wong (1998) evaluate the planning methods and techniques from an historic perspective. While Batey and Breheny examine the history of planning methodology and offer a framework for the assessment of Anglo-American theory and practice, Wong addresses the planning methods and techniques in the 1990s while evaluating the changing philosophy of planning from an historic perspective. Wong focuses, in particular, on the rising importance of environmentalism and the professional interest in the development of sustainability indicators, and the process and methods used to assess environmental impacts and the rapid development of information technology and computing software such as geographic information system (GIS). However, she emphasizes that these new trends do not necessarily signify major progress in the development of planning methods and techniques.

- The next contribution discusses the qualitative approaches to the city. Jacobs (1993) argues that approaches relying on qualitative methods have had an uncertain and generally marginal status within urban studies and qualitative approaches to understanding the urban have long been overshadowed by the hegemony of positivism within mainstream urban studies. She reviews the significant changes and various developments -such as the transformation of the relationship between general theory and the specific case study, the expansion of the repertoire of qualitative methods through an increased recognition of symbolic and representational realms (figurative and discursive) and the role they play in the constitution and mediation of social and material processes- which have led to a revitalisation and diversification of qualitative approaches in urban studies.

- Wegener (1994) views the current state of the art of operational "integrated" urban models and defines a framework for the classification and evaluation of urban models, using as criteria comprehensiveness, overall structure, theoretical foundations, modelling techniques, dynamics, data requirements, calibration and validation, operationality, and actual and potential applications. He compares 12 contemporary operational urban models of varying comprehensiveness and sophistication that have been or are being applied to real-life metropolitan regions for research and/or policy analysis and that were selected from the work at twenty urban modelling centres in the world where research and development in urban modelling is actively conducted. On 
the basis of this comparison, he discusses also the most promising avenues to further improvement and diffusion of these kinds of models.

This overview shows that the planning methods and techniques have become more comprehensive, more sophisticated and more dynamic over the years. The literature on planning methods shows also that, besides the developments in quantitative approaches, more focus on qualitative approaches has emerged in recent years. On the other hand, the attention has increasingly turned to the way one might integrate results from evaluations that use different strategies, carried out from different perspectives and using different methods. Actually, there is a clear need for qualitative and quantitative meta-analytical experiments and the developments in methodological meta-integration seem to determine the future of planning methodologies and approaches.

\section{What is a good planning process at the interface of citizen participation and urban governance?}

The final section focuses on community involvement in urban planning. The planning literature refers to this phenomenon with different concepts. Among the different concepts, “community involvement", “community empowerment", "public participation” or "citizen participation" and "community government" can be mentioned. Citizen or public participation can be defined as the means by which members of the community are able to take part in the shaping of policies and plans that will affect the local environment in which they live. The demand for participation stems from a growing concern that the decisions which determine the quality of life in a community should reflect the wishes of those who live there rather than represent purely technical solutions imposed from outside. This concept of participation implies that people should have access to the choices and proposals open to a planning authority and should be able to put forward ideas and comments at every stage in the planning process, from the initial identification of social objectives to the detailed implementation of plans. Therefore, the best plans are usually those that represent the collective will of the community, and participation in the planning process, in a real sense, means a decentralization of power.

The decentralization of power in the decision-making process has shifted the role of government from one of providing facilities to enabling the public to provide and deploy facilities, or to facilitate community improvement. Therefore, community participation has become a basic element of the community development process. The community can be involved in many aspects of this process such as problem identification, planning, implementation and the management and maintenance of facilities in the community. The shift in the roles of central and local governments as well as in the community has led also a conceptual shift from 'government' toward 'governance'. Actually, governance has been accepted as a way of management of urban development at all levels.

This last section consists of seven articles which focus on different dimensions of community involvement in urban planning on the basis of several questions such as "What is citizen participation and what is its relationship to the social imperatives of our time?", "How the citizen participation process can be speeded up and better organized?", "What happens to government when people participate ?", "What do we wish to have performed by 
participation programme?", "Where do we wish the participation road to lead? What are the goals ?", "Why do we talk about 'urban governance' these days, much more than we discuss urban management?", "What types of 'governance infrastructures' have the capacity to release imaginative and innovative activities in city regions?”. The contributions discussed below reflect the debate about community involvement in urban planning from the end of the 1960 s to the 2000 s.

- "What is citizen participation and what is its relationship to the social imperatives of our time?" In order to answer this question Arnstein (1969) develops a typology of citizen participation by using examples from three federal social programmes: urban reneval, antipoverty, and modal cities. Her typology is arranged in a ladder pattern with each rung corresponding to the extent of citizens' power in determining the plan and/or program. She defines her typology in three levels, from the level of "nonparticipation" to the levels of "tokenism" and "citizen power", which consist of eight rungs viz., "manipulation”, "therapy”, "informing”, "consultation”, "placation”, "partnership", "delegated power" and "citizen control". On the basis of this ladder she answers the question: "what is citizen participation" as the redistribution of power, as the strategy in determining how information is shared, goals and policies are set, and as a significant social reform.

- "How the citizen participation process can be speeded up and better organized ?" The second contribution on community involvement in urban planning written by Williams (1976) addresses various facets of citizen participation in city and regional planning based on several decades of experience and experimentations in the Western United States. Williams introduces the 'conference approach' which is a more accelerated system of citizen participation that utilizes short conferences including public officials as well as citizens in the process. According to this approach, conference groups are not expected to prepare plans and solve planning problems, but are expected to help set up a value system to help the planner solve them. This approach shows substantial promise in reducing both the overall and the elapsed time needed for citizen participation.

- "Who are the citizens ?", "How can the citizens participate ?", "What are the participants' interests?”. On the basis of these questions Johnson (1984) examines participation and participants in local planning and he defines five forms of participation flow into a broadly-flowing stream. The five forms of participation include constituent, consultative, definitive, implementive and evaluative participation. He emphasises also that, as in a real river, these flows can blend with each other.

- "What happens to government when people participate ?" In their article, Campbell and Marshall (2000) look beyond the operational concerns to explore in detail the rationales for public involvement in planning and to examine the potentiality for the realization of these goals by investigating what happens to government, and more specifically planning, when people participate at local levels. Their analysis is based on a conceptual framework which focuses on the interests served by public involvement. Their findings show that the need for planners to be much more sophisticated in the way that handle the problematic of balancing personal interests with the 
collective good, including how different forms of knowledge can be reconciled.

- Next, Sanoff (2000) examines community participation from a historical perspective and discusses different and changing viewpoints. In order to conceptualize the issue he asks the main questions of: Who, what, where, how, and when?, "Who are the parties to be involved in participation?", "What do we wish to have performed by participation programme?", "Where do we wish the participation road to lead?" "What are the goals?", "How should people be involved?", "When in the planning process is participation needed or desired?". Then, he describes the stages of participation, who should participate and the consequences of participation.

- The following article by Kearns and Paddison (2000) focuses on the new challenges for urban governance. "Why do we talk about 'urban governance' these days, much more than we discuss urban management?" In order to answer this question they identify several ways in which the urban context has changed to challenge urban management and has helped to give rise to urban governance. Among the most momentous shifts they emphasize economic globalisation which means a loss of control over urban economies, and new activities and responses for urban governments, interurban competition, changing urban-regional interrelationships in a global world, cross-border cooperation and trans-frontier networking. While defining governance as "... the capacity to get things done in the face of complexity, conflict and social change: organisations, notably but not only urban governments, empower themselves by blending their sources, skills and purposes with others.", they illuminate and illustrate three aspects of the present and emerging situation, viz. urban governance is a multilevel activity, for governance itself political and administrative processes are almost as important as what is done and, urban governance seeks new ways to be creative, to build strengths and to access and utilise resources.

- Finally, Healey (2004) examines the relationship between 'creativity' and 'innovation', and the forms and practices of 'governance' in an urban context. "What types of 'governance infrastructures' have the capacity to release imaginative and innovative activities in city regions ?", "What interventions help to transform governance cultures to generate such capacity?", "What 'imaginative resources' and mobilising power help to enrich contexts to foster the 'mainstreaming' of successful experiments?”. On the basis of these three questions focusing on initiatives to promote new forms of governance to guide the development of the places of cities and city regions she addresses, in particular, the 'double' creativity of governance both in terms of its potential to foster creativity in social and economic dynamics and to creatively transform its own capacities. She advocates a multi-level approach to the dimension of urban governance through which to identify qualities of governance activity, which, in specific contexts, have the potential to encourage creativity and innovation. She develops a three-level approach to the interacting dimensions of governance linking episodes, processes and cultures.

The above-mentioned dissussions clearly show that the planning process has transformed in a radical way over the years from citizen participation to urban governance which means the increasing decentralization of power. The decentralization of power in the 
decision-making process has shifted the role of government from one of providing facilities to enabling the public to provide and deploy facilities, or to facilitate community improvement. Therefore, the blueprint planning has been replaced by more participatory and evolutionary forms of planning and in this participatory form of planning, community participation has become a basic element of the community development process.

\section{Towards a new perspective}

The previous observations taken from the history of urban planning-based on a repeated use of seven distinct perspectives-has brought to light various important lessons and needs for new research endeavours in urban planning. They will be summarized here in seven focal points :

- Urban planning has exhibited a dynamic trajectory that appears to have run largely parallel to major trends in the general planning literature.

- The belief in blueprint planning-based on 'makebility' of society-has largely been given up and is replaced by more democratic (e.g., participatory and evolutionary) forms of planning.

- The ongoing debate on urban planning with due emphasis on its substance and scope has prompted the need to address the needs of urban citizens ('planning for and by the people').

- The urban planning discipline has become a transdisciplinary combination of many disciplines focused on the development of urban areas (e.g., urban architecture, urban ecology, urban geography, political science, urban economics, law etc).

- The methodology of urban planning is a smart mix of the toolboxes offered by the constituent disciplines of urban planning, which prompts the need for a methodological meta-integration.

- Urban planning exhibits an enormous variety of concerns, focal points, political constellations and model applications, so that there is a clear need for qualitative and quantitative meta-analytical experiments, with a view to the derivation of general lessons to other cases ('value transfer').

- Finally, urban planning is a discovery tour with many handles. The intensification of barriers and ways to overcome them is another major challenge to urban planning; the study into critical success factors is a major task for effective urban planning in the future.

\section{References}

[1] Alonso, W., "What are New Towns for ?," Urban Studies, Vol. 7, No. 1, 1970, pp. 37-55.

[2 ] Arnstein, S., "A ladder of citizen participation,” JAIP, 35, 1969, pp. 216-224.

[ 3 ] Banfield, E.C., "Ends and Means in Planning," International Social Science Journal, XI (3), 1959.

[ 4 ] Bartone, C., "Environmental Challenge in Third World Cities," Journal of the American Planning Association, Vol. 57, No. 4, 1991, pp. 411-415.

[5] Batey, P.W.J. and Breheny, M.J., "The history of planning methodology : a framework for the assessment of Anglo-American theory and practice," Reading Geographical Papers, Vol. 79, 1982.

[6 ] Blumenfeld, H., "The Economic Base of the Metropolis," JAIP, Vol. 21, No. 4, 1955, pp. 114-132.

[ 7 ] Campbell, H. and Marshall, R., "Acting on Principle: Dilemmas in Planning Practice," Planning 
Practice and Research, Vol. 13, No. 2, 1998, pp. 117-128.

[ 8 ] Campbell, H. and Marshall, R., "Public Involvement and Planning : Looking Beyond the One to the Many,” International Planning Studies, Vol. 5, No. 3, 2000, pp. 321-344.

[9] Chadwick, G., A Systems View of Planning: Towards a Theory of the Urban and Regional Planning Process, Pergamon Press, 1971.

[10] Chapin, F.S. Jr., "Taking Stock of Techniques for Shaping Urban Growth,” JAIP, Vol. 29, No. 2, 1963, pp. 76-87.

[11] Choguill, C.L., "Editorial : Sustainable cities: Urban policies for the future," Habitat International, Vol. 17, No. 3, 1993, pp. 1-12.

[12] Drakakis-Smith, D., “Third World Cities: Sustainable Urban Development, I," Urban Studies, Vol. 32, No. 4-5, 1995, pp. 659-677.

[13] Faludi, A., “The Performance of Spatial Planning," Planning Practice and Research, Vol. 15, No. 4, 2000, pp. 299-318.

[14] Forester, J., "Reflections on the Future Understanding of Planning Practice," International Planning Studies, Vol. 4, No. 2, 1999, pp. 175-194.

[15] Friedmann, J., “Planning Theory Revisited,” European Planning Studies, Vol. 6, No. 3, 1998, 245254.

[16] Gaspar, J. and Glaeser, E., "Information Technology and the Future of Cities," Journal of Urban Economics, Vol. 43, 1998, pp. 136-156.

[17] Gilbert, A., "Third World Cities : Housing, Infrastructure and Servicing," Urban Studies, Vol. 29, No. 3-4, 1992, pp. 435-460.

[18] Glaeser, E.L., “Are cities dying ?,” Journal of Economic Perspectives, Vol. 12, No. 2, 1998, 139-160.

[19] Gordon, P. and Richardson, H.W., "Are Compact Cities a Desirable Planning Goal ?," Journal of the American Planning Association, Vol.63, No. 1, 1997, pp. 95-106.

[20] Graham, S. and Marvin, S., "Telematics and the convergence of urban infrastructure ; implications for contemporary cities,” Town Planning Review, Vol. 65, 1994, pp. 227-242.

[21] Graham, S. and Healey, P., "Relational Concepts of Space and Place: Issues for Planning Theory and Practice," European Planning Studies, Vol. 7, No. 5, 1999, pp. 623-646.

[22] Hall, P., "Planning, Planners and Plans," in P. Hall, Urban and Regional Planning, Routledge, 1992, pp. 1-11.

[23] Hall, P., "The Future of the Metropolis and its Form,” Regional Studies, Vol. 31, No. 3, 1997, pp. 211-220.

[24] Hardoy, J.E. and Satterthwaite, D., "Urban change in the third world: Are recent trends a useful pointer to the urban future?," Habitat International, Vol. 10, No. 3, 1986, 33-52.

[25] Harris, B., "Plan or Projection: An Examination of the Use of Models in Planning," JAIP, Vol. 26, No. 4, 1960, pp. 365-272.

[26] Healey, P., “Creativity and Urban Governance,” Policy Studies, Vol. 25, No. 2, 2004, pp. 87-102.

[27] Jacobs, J., "The generators of Diversity' in J. Jacob, The Death and Life of Great American Cities, Vintage, 1961, pp. 143-151.

[28] Jacobs, J.M., "The City Unbound: Qualitative Approaches to the City," Urban Studies, Vol. 30, No. 4-5, 1993, pp. 827-848.

[29] Johnson, W.C., "Participation and Participants" in W.C. Johnson, Citizen Participation in Local Planning in the U.K. and U.S.A. : A Comparative Study, Pergamon Press, 1984, pp. 164-171.

[30] Kearns, A. and Paddison, R., "New Challenges for Urban Governance," Urban Studies, 37, No. 56, 2000, pp. 845-850.

[31] Leitmann, J., Bartone, C. and Bernstein, J., "Environmental management and urban development : issues and options for Third World Cities," Environment and Urbanization, Vol. 4, No. 2, 1992, pp. 131-140.

[32] Levy, J.M., Contemporary Urban Planning, Prentice Hall, 1997. 
[33] Lynch, K. and Rodwin, L., “A Theory of Urban Form,” JAIP, Vol. 24, No. 4, 1958, pp. 201-214.

[34] Muller, J., "Paradigms and Planning Practice: Conceptual and Contextual Considerations," International Planning Studies, Vol. 3, No. 3, 1998, pp. 287-302.

[35] Mumford, L., "The neighbourhood and neighbourhood unit," Town Planning Review, Vol. 24, 1953, pp. 256-270.

[36] Rapoport, A., "Environmental quality, metropolitan areas and traditional settlements," Habitat International, Vol. 7, No. 3-4, 1983, pp. 37-63.

[37] Richardson, H., "Optimality in city size, systems of cities and urban policy : a sceptic's view," Urban Studies, 1972, pp. 29-47.

[38] Roberts, M., An Introduction to Town Planning Techniques, Hutchinson Educational, 1974.

[39] Sanoff, H., "Participation Purposes," in H. Sanoff, Community Participation Methods in Design and Planning, John Wiley and Sons, 2000, pp. 1-36.

[40] Sassen, S., "Impacts of Information Technologies on Urban Economic and Politics," International Journal of Urban and Regional Research, Vol. 25, No.2, 2001, pp. 411-418.

[41] Travis, A.S., "Planning as Applied Ecology: The Management of Alternative Futures," Town Planning Review, Vol. 48, No. 1, 1977, pp. 5-16.

[42] Wegener, M., "Operational urban models: State of the art," Journal of the American Planning Association, Vol. 60, No. 1, 1994, pp. 17-29.

[43] Turner, A., "Urban planning in the developing world: Lessons from experience," Habitat International, Vol. 16, No. 2, 1992, pp. 113-126.

[44] White, R.R., Strategic Decisions for Sustainable Urban Development in the Third World, Third World Planning Review, Vol. 16, No. 2, 1994, pp. 103-127.

[45] Williams, S.H., "Citizen Participation in City and Regional Planning," Town Planning Review, Vol. 47, No. 4, 1976, pp. 349-358.

[46] Wilson, A.G., "Models in Urban Planning: A Synoptic Review of Recent Literature," Urban Studies, Vol. 5, No. 3, 1968, pp. 249-276.

[47] Wong, C., "Old Wine in A New Bottle? Planning Methods and Techniques in the 1990s," Planning Practice and Research, Vol. 13, No. 3, 1998, pp. 221-236.

[48] Wurster, C.B., "The form and structure of the future urban complex," in L Wingo (ed), Cities and space, Johns Hopkins UP, 1963, pp. 73-102.

[49] Yiftachel, O., "Towards a new typology of urban planning theories," Environment and Planning B : Planning and Design, Vol.16, 1989, pp. 23-39. 